\title{
Multiple Time Scale Variability of the Sea Surface Salinity Dipole Mode in the Tropical Indian Ocean $\mathscr{}$
}

\author{
YUHONG ZHANG AND YAN DU \\ State Key Laboratory of Tropical Oceanography, South China Sea Institute of Oceanology, \\ Chinese Academy of Sciences, Guangzhou, China \\ MiNG FENG \\ Commonwealth Scientific and Industrial Research Organisation, Oceans and Atmosphere, \\ Indian Ocean Marine Research Centre, Crawley, Western Australia, and \\ Centre for Southern Hemisphere Oceans Research, Commonwealth Scientific and Industrial Research \\ Organisation, Oceans and Atmosphere, Hobart, Tasmania, Australia
}

(Manuscript received 25 April 2017, in final form 2 October 2017)

\begin{abstract}
In this study, multiple time scale variability of the salinity dipole mode in the tropical Indian Ocean (S-IOD) is revealed based on the 57-yr Ocean Reanalysis System 4 (ORAS4) sea surface salinity (SSS) reanalysis product and associated observations. On the interannual time scale, S-IOD is highly correlated with strong Indian Ocean dipole (IOD) and ENSO variability, with ocean advection forced by wind anomalies along the equator and precipitation anomalies in the southeastern tropical Indian Ocean (IO) dominating the SSS variations in the northern and southern poles of the S-IOD, respectively. S-IOD variability is also associated with the decadal modulation of the Indo-Pacific Walker circulation, with a stronger signature at its southern pole. Decadal variations of the equatorial IO winds and precipitations in the central IO force zonal ocean advection anomalies that contribute to the SSS variability in the northern pole of S-IOD on the decadal time scale. Meanwhile, oceanic dynamics dominates the SSS variability in the southern pole of S-IOD off Western Australia. Anomalous ocean advection transports the fresher water from low latitudes to the region off Western Australia, with additional contributions from the Indonesian Throughflow. Furthermore, the southern pole of S-IOD is associated with the thermocline variability originated from the tropical northwestern Pacific through the waveguide in the Indonesian Seas, forced by decadal Pacific climate variability. A deepening (shoaling) thermocline strengthens (weakens) the southward advection of surface freshwater into the southern pole of S-IOD and contributes to the high (low) SSS signatures off Western Australia.
\end{abstract}

\section{Introduction}

Ocean salinity is a good indicator of the status of the global hydrological cycle. Sea surface salinity (SSS) trends in the global ocean observed in the last half century have been used to reveal global hydrologic cycle and climate changes (Antonov et al. 2002; Curry et al. 2003; Boyer et al. 2005; Durack and Wijffels 2010; Durack et al. 2012). A significant SSS trend in the tropical Indo-Pacific region was observed from Argo

Supplemental information related to this paper is available at the Journals Online website: https://doi.org/10.1175/JCLID-17-0271.s1.

Corresponding author: Yan Du, duyan@scsio.ac.cn floats in the last decade, attributed to decadal adjustment of the Walker circulation of the Indo-Pacific (Du et al. 2015).

El Niño-Southern Oscillation (ENSO) induced strong interannual variability of SSS in the tropical Pacific (Delcroix and McPhaden 2002; Singh et al. 2011; Qu and Yu 2014; Qu et al. 2014). Strong salinity variations have also been found to be associated with the Indian Ocean dipole (IOD) events (Masson et al. 2004; Thompson et al. 2006; Vinayachandran and Nanjundiah 2009; Grunseich et al. 2011), and the IOD associated ocean processes and atmospheric forcing dominate the variability of salinity in the tropical Indian Ocean (IO) (Subrahmanyam et al. 2011; Zhang et al. 2013; Durand et al. 2013; Nyadjro and Subrahmanyam 2014; Du and Zhang 2015). Based on 10-yr Argo observations, 
Y. Zhang et al. (2016) revealed a meridional salinity dipole mode in the tropical Indian Ocean (S-IOD), with low SSS anomaly (SSSa) near the equator and high SSSa in the southeastern IO as its positive phases. They found that the S-IOD is closely correlated with the IOD and ENSO variability.

Despite the research progress on the interannual variations of SSS in the Indo-Pacific, decadal SSS variability and its association with modes of climate variability are less investigated. This study aims to investigate the SSS variability in the tropical IO on different time scales based on the 57-yr ORAS4 data. Decadal variability of the S-IOD is found to be comparable to its interannual variability, and its connection to the decadal climate variability in the Indo-Pacific region is revealed.

The paper is organized as follows. After a brief description of the data and methods in section 2, we describe the S-IOD events occurring in the period from 1958 to 2014 and discuss their relationship with the IOD and ENSO in section 3. The interannual and decadal S-IOD variations and the associated key climate processes are described in section 4. Discussion is given in section 5. Results are summarized in section 6.

\section{Data and method}

\section{a. Data}

The Ocean Reanalysis System 4 (ORAS4) (Balmaseda et al. 2013) data provided by the European Centre for Medium-Range Weather Forecasts (ECMWF) for the period 1958-2014 are used in this study. The ORAS4 is based on the Nucleus for European Modelling of the Ocean (NEMO) model and the uses the NEMO variational data assimilation system (NEMOVAR), which is a variational data assimilation system designed to produce an analysis of the global ocean. The ocean model has 42 vertical levels with the upper 18 levels within $200 \mathrm{~m}$, and the first level has a 10-m thickness. We use the ORAS4 salinity, horizontal currents, and temperature in the upper-500-m layers, and in this paper $\mathrm{SSH}$ and the anomalies in ORAS4 are with respect to the climatology over the period 1958-2014.

The ocean model is forced by daily fluxes of solar radiation, total heat flux, evaporation minus precipitation, and surface wind stress that are taken from the ERA-40 (Uppala et al. 2005) from September 1957 to December 1988, the ERA-Interim (Dee et al. 2011) from January 1989 to December 2009, and the ECMWF operational reanalysis archive from January 2010 onward. ORAS4 assimilates temperature and salinity profiles from the EN3 version 2a (v2a) XBT biascorrected database (1958-2009), which includes XBT,
CTD, Argo, and mooring data, and data from the realtime Global Telecommunications System (GTS) after 2010. The information of sea surface temperature (SST) and global mean sea level variations is used to correct the heat and freshwater fluxes from the atmospheric reanalysis and to modify the heat and freshwater budget, respectively. SST and sea ice are from the ERA-40 archive prior to November 1981, from the NCEP optimum interpolation (OI) version 2 (v2) weekly product (Reynolds et al. 2002) from December 1981 to December 2009, and from Operational Sea Surface Temperature and Sea Ice Analysis (OSTIA) (Stark et al. 2007) from January 2010 onward. The sea level data are provided by AVISO (http://www.aviso.altimetry.fr/).

The Global Precipitation Climatology Project (GPCP) version 2.2 (Adler et al. 2003; Huffman et al. 2009) monthly data are available from 1979 to the present with a resolution of $2.5^{\circ} \times 2.5^{\circ}$, reconstructed into a $1^{\circ} \times$ $1^{\circ}$ grid using linear interpolation in this study. The evaporation is from the objectively analyzed air-sea fluxes (OAFlux) with a resolution of $1^{\circ} \times 1^{\circ}$ (Yu and Weller 2007). Both of them are used to calculate freshwater flux [evaporation minus precipitation $(E-P)$ ] for the period 1979-2014. A new version of the crosscalibrated multiplatform (CCMP, version 2.0) (Atlas et al. 2011; Wentz et al. 2015) gridded surface vector winds with a resolution of $0.25^{\circ} \times 0.25^{\circ}$ is now available from Remote Sensing Systems (RSS). The CCMP data are obtained by combining version 7 of the RSS radiometer wind speeds, QuikSCAT and ASCAT wind vectors, moored buoy wind data, and ERA-Interim model wind fields using a variational analysis method (VAM) (Atlas et al. 2011). The level-3.5 CCMP version 2.0 monthly data spanning from 1988 to 2014 are used in this study. The anomalies from GPCP and CCMP are with respect to the climatologies over their own periods of datasets. The most recent version of the NOAA Extended Reconstructed SST (ERSST.v3b) analysis data with a resolution of $2^{\circ} \times 2^{\circ}$ from the National Climatic Data Center is used to construct the dipole mode index (DMI) for the IOD, following the definition in Saji et al. (1999), and the Niño-3.4 index $\left(5^{\circ} \mathrm{S}-5^{\circ} \mathrm{N}, 170^{\circ}-120^{\circ} \mathrm{W}\right)$ for ENSO in the period from 1958 to 2014.

\section{b. Method}

The mixed layer salinity evolution equation can be expressed as (Feng et al. 1998)

$$
\frac{\partial S}{\partial t}=-\left(u \frac{\partial S}{\partial x}+v \frac{\partial S}{\partial y}\right)-\frac{S_{0}(P-E)}{h}-w_{e} \frac{S-S_{-h}}{h},
$$

where $S$ is the mixed layer salinity; $u$ and $v$ are the zonal and meridional velocities, respectively; $S_{0}$ is the SSS; 
$P$ and $E$ are the precipitation and evaporation rates, respectively; the depth of the mixed layer $h$ is calculated from density based on a temperature criterion of $0.8^{\circ} \mathrm{C}$ decrease from the temperature at $10 \mathrm{~m}$ (Kara et al. 2000); $S_{-h}$ is the salinity right below the mixed layer, and $w_{e}=d h / d t+\left.w\right|_{-h}$ is the entrainment velocity. The salinity advection term can be decomposed into three parts as

$$
\begin{aligned}
& -\left[\left(\bar{u} \frac{\partial \bar{S}}{\partial x}+\bar{v} \frac{\partial \bar{S}}{\partial y}\right)+\left(\bar{u} \frac{\partial S^{\prime}}{\partial x}+\bar{v} \frac{\partial S^{\prime}}{\partial y}+u^{\prime} \frac{\partial \bar{S}}{\partial x}+v^{\prime} \frac{\partial \bar{S}}{\partial y}\right)\right. \\
& \left.+\left(u^{\prime} \frac{\partial S^{\prime}}{\partial x}+v^{\prime} \frac{\partial S^{\prime}}{\partial y}\right)\right] .
\end{aligned}
$$

The first part and the third part are the mean advection and the higher-order nonlinear terms, which are not considered in this study. The middle part is the ocean advection caused the salinity anomaly, which contains the zonal and meridional advection of anomalous salinity due to mean currents $-\left(\bar{u} \partial S^{\prime} / \partial x+\bar{v} \partial S^{\prime} / \partial y\right)$ and the zonal and meridional advection associated with mean SSS gradient and anomalous currents $-\left(u^{\prime} \partial \bar{S} / \partial x+v^{\prime} \partial \bar{S} / \partial y\right)$. The thickness of the barrier layer is defined as the difference between the isothermal depth based on a temperature difference of $0.8^{\circ} \mathrm{C}$ from the temperature at $10 \mathrm{~m}$ and the mixed layer depth (MLD). We test the significance of the regression coefficients using the standard two-tailed Student's $t$ test. Following Bretherton et al. (1999), the effective degrees of freedom $N^{*}$ were calculated as

$$
N^{*}=(N-1) \frac{1-r_{x x}(d \tau) r_{y y}(d \tau)}{1+r_{x x}(d \tau) r_{y y}(d \tau)},
$$

where $r_{x x}(d \tau)$ and $r_{y y}(d \tau)$ are the 12-month-lag autocorrelation of the S-IOD index and the variables, respectively, and $N$ is 57 .

\section{S-IOD events}

The first EOF mode of the 57-yr ORAS4 reanalysis salinity data represents the S-IOD, with contrasting salinity anomalies in the equatorial IO and the tropical southeastern IO (Fig. 1a). The first principal component (PC1) shows significant interannual and decadal variability and long-term trend (Fig. 1b). The S-IOD pattern persists in the first EOF mode even when linear trends in the salinity data are removed, only with weaker signature in the southern pole. A similar pattern could be found in Argo observations starting from 2004, with a strong SSS signature in the northern pole and a weak SSS signature in the southern pole (Y. Zhang et al. 2016). Previous studies indicated that the SSS in the southeastern IO has dramatically decreased in the most
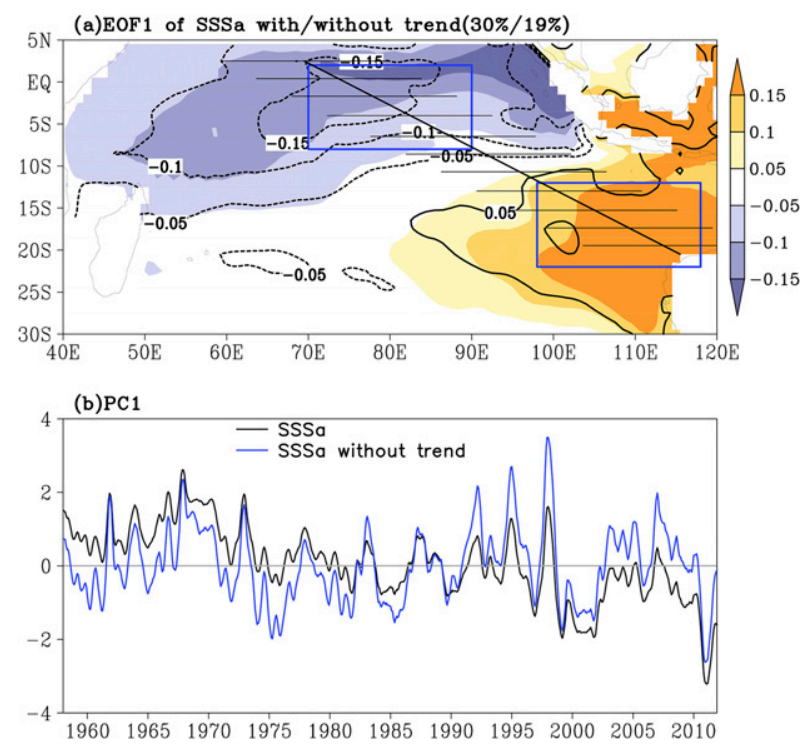

FIG. 1. EOF analysis of the ECMWF ORAS4 SSS anomaly. (a) First EOF mode of SSSa with (shaded; psu) and without (contours; psu) long-term linear trend. (b) The principal component with (black curve) and without (blue curve) long-term linear trend. The two blue boxes in (a) are the averaged regions in the south equatorial IO and the southeastern IO for the S-IOD index, and the thick declining line denotes the location of the transect. [The parallelogram region filled with the short black zonal lines in (a) is the averaged region for the anomalies in Fig. 6.]

recent two decades (Du et al. 2015), compared with weak trends during previous decades (Boyer et al. 2005; Durack and Wijffels 2010). The first EOFs with and without the long-term linear trend account for $30 \%$ and $19 \%$ of the total variances, respectively.

The PC1 of detrended salinity data shows similar variation with the S-IOD index, which is defined as the SSSa difference between the southeastern IO $\left(22^{\circ}-12^{\circ} \mathrm{S}, 98^{\circ}-118^{\circ} \mathrm{E}\right)$ and the central equatorial IO $\left(8^{\circ} \mathrm{S}-2^{\circ} \mathrm{N}, 70^{\circ}-90^{\circ} \mathrm{E}\right)(\mathrm{Y}$. Zhang et al. 2016), with a correlation coefficient of 0.85 (Fig. 2a). Following Y. Zhang et al. (2016), an S-IOD event is defined when the S-IOD index is larger than 1.2 times of its standard deviation and persists more than four months during the developing to mature phases from boreal fall to winter. There are seven positive S-IOD events and five negative S-IOD events in the last 57 years with the above criterion. The positive events occur in years 1965/66, 1967/68, 1972/73, 1991/92, 1994/95, 1997/98, and 2006/07. The negative events occur in years 1973/74, 1984/85, 1998/99, 2000/01, and 2010/11. Similarly, we define a strong IOD event when DMI is larger than 1.2 times the standard deviation for two consecutive months during fall, and define the ENSO event when the Niño-3.4 index is larger than one standard deviation for two consecutive months during the fall-winter seasons. Most of the S-IOD events 

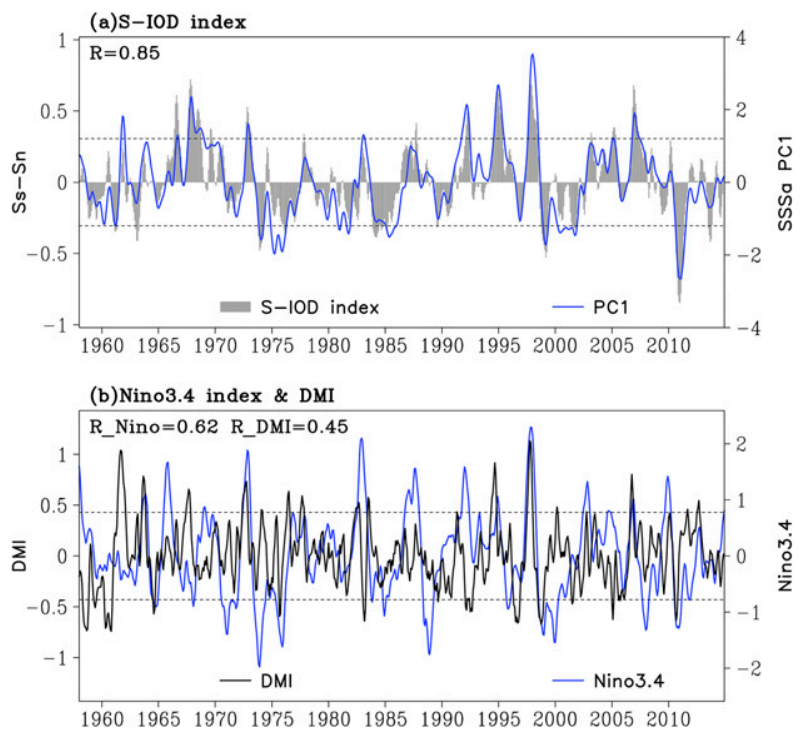

FIG. 2. The time series of the S-IOD indices, DMI, and Niño-3.4 index. (a) The difference of the SSSa between the southeastern IO $\left(22^{\circ}-12^{\circ} \mathrm{S}, 98^{\circ}-118^{\circ} \mathrm{E}\right)$ and the central equatorial IO $\left(8^{\circ} \mathrm{S}-2^{\circ} \mathrm{N}, 70^{\circ}-\right.$ $90^{\circ} \mathrm{E}$ ), and the PC1 of the SSSa in the tropical IO. (b) The DMI and the Niño-3.4 index. The dashed lines show 1.2 times the standard deviation of the S-IOD indices in (a) and of the DMI in (b), and one standard deviation of the Niño-3.4 index in (b).

concur with the strong IOD events, except for the 1965/ 66 positive event and the 1973/74 and 1984/85 negative events, and with ENSO events, except for the 1967/68 positive event. The S-IOD index shows high correlation with DMI and Niño-3.4 indices, with correlation coefficients higher than 0.4 when S-IOD lags by 3 months and 0.6 when S-IOD lags by 2 months, both significant at 95\% confidence level (Fig. 2b).

The evolution of the S-IOD event could be presented by the composite of seven positive and five negative S-IOD events (see Figs. S1 and S2 in the supplemental material). The positive (negative) S-IOD event starts in July-August with low (high) SSSa in the equatorial region and high (low) SSSa in the southeastern IO, corresponding to the westward (eastward) current anomalies and precipitation decrease (increase). The S-IOD develops to the mature phase in NovemberDecember, lagging the IOD by 2 months. Then it persists 10 months until the next September-October. This result is consistent with the analysis from 10 years of Argo observations (Y. Zhang et al. 2016), further indicating that the S-IOD event is a distinct mode in the IO, closely related with both strong IOD and ENSO events. Moreover, the SSSa in the southern pole shows a larger signature when the low-frequency variability is considered, implying that the S-IOD features a multiple time scale variability.
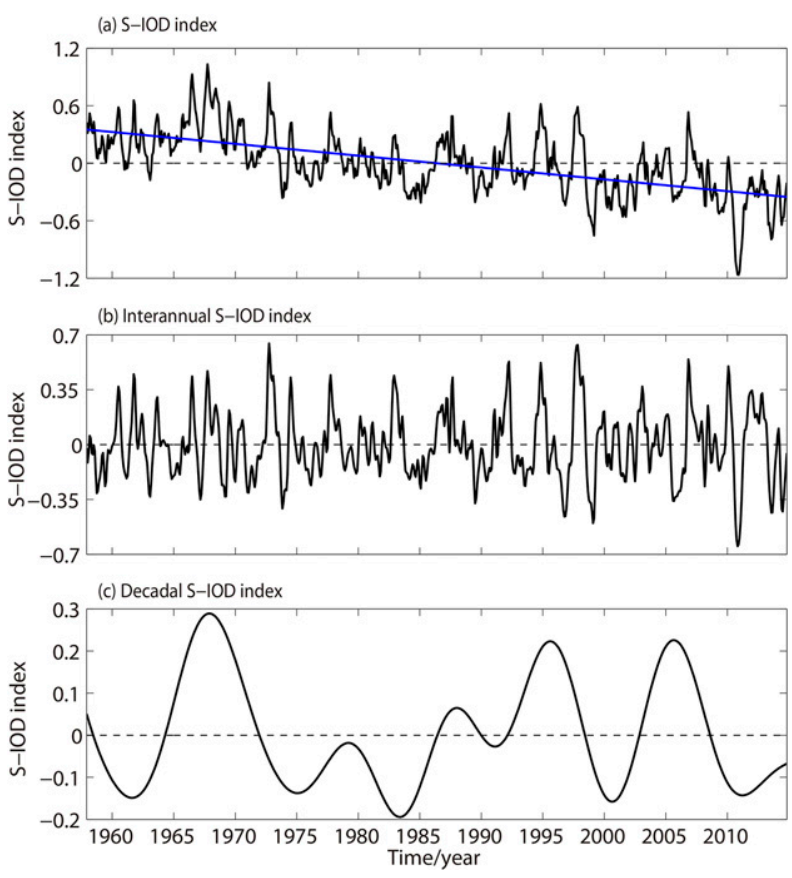

FIG. 3. The multiple time scale of S-IOD index: (a) the S-IOD index (black curve; psu) and the long-term linear trend (blue line; psu), (b) the interannual S-IOD index, and (c) the decadal S-IOD index. The interannual S-IOD index is obtained by applying a 484-month bandpass filter, and the decadal S-IOD index is obtained by applying an 84-month low-pass filter.

\section{The multiple time scale variability of the S-IOD and relationships with the climate modes}

\section{a. Multiple time scale variability of the $S-I O D$ index}

The S-IOD index shows a strong long-term linear trend for the period from 1958 to 2014 . The trend is more than 2 times the standard deviation of the S-IOD index without trend (0.26), as indicated by the PC1 (Fig. 3a). Figure $3 \mathrm{a}$ also suggests decadal or multidecadal variability of the S-IOD. More positive events occur before the mid-1970s and after the 1990s, and more negative events occur in between (Fig. 2a). Fourier spectrum analysis shows three peaks in the spectra of S-IOD index, with interannual variability with a 5 -yr cycle, decadal variability with a 12 -yr cycle, and interdecadal variability with an approximately $30-y$ r cycle (Fig. S3 in the supplemental material). For the approximately $30-y r$ cycle, we hardly provide a credible result since we only have two cycles $(57 \mathrm{yr})$, so we combined it with the decadal variability. Thus, in the following, we focus on the interannual and the decadal variability (Figs. 3b,c).

\section{b. Interannual variability}

Figures $4 \mathrm{a}-\mathrm{c}$ show the regression of contemporaneous SSS, and 2-month-lead precipitation, currents, SST, 

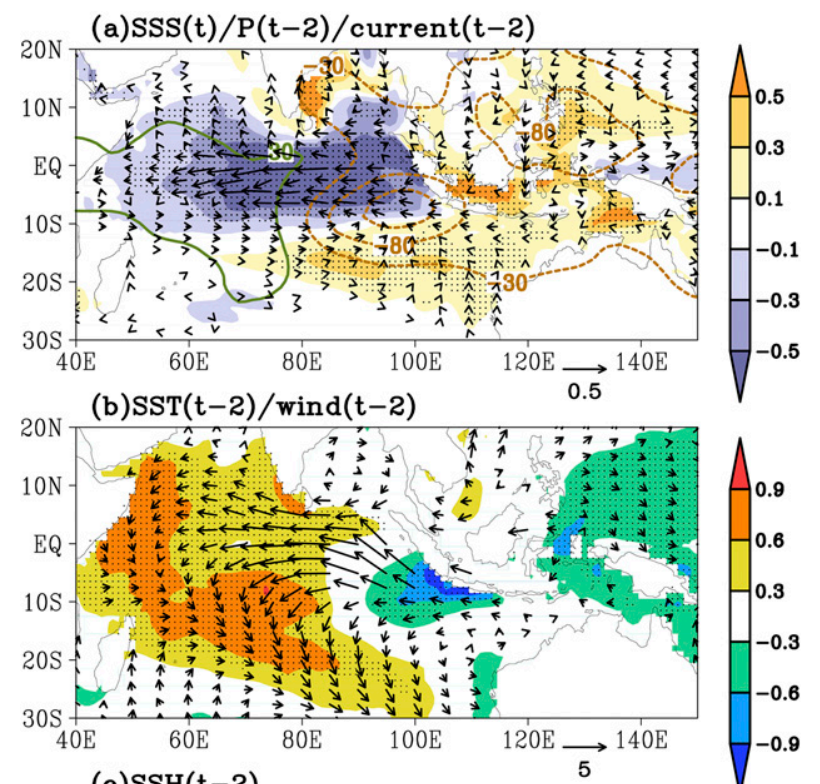

(c) $\operatorname{SSH}(t-2)$

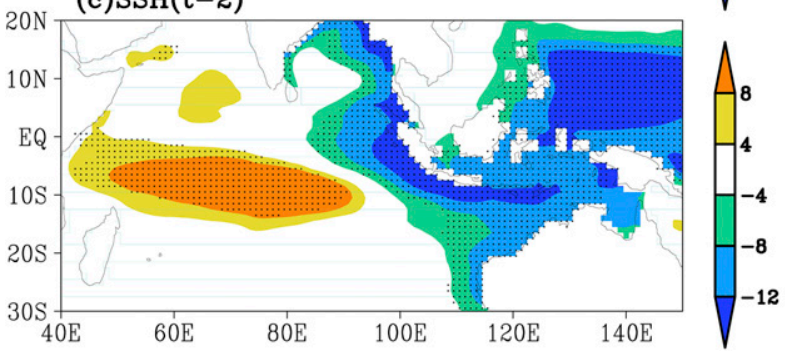

FIG. 4. The regression upon the interannual S-IOD index: (a) SSS (shaded; psu) and 2-month-lead precipitation (contours; mm month ${ }^{-1}$ ) and the currents (vectors; $\mathrm{m} \mathrm{s}^{-1}$ ); (b) 2-month-lead SST (shaded; ${ }^{\circ} \mathrm{C}$ ) and wind (vectors; $\mathrm{m} \mathrm{s}^{-1}$ ); and (c) 2-month-lead SSH anomalies. A 4-84-month bandpass filter is applied to all variables. The dotted region indicates that the values are significant at the $95 \%$ confidence level.

wind, and SSH anomalies on the interannual S-IOD index. The results show a meridional dipole mode with significant SSSa signature in the central equatorial IO and weak SSSa signature in the southeastern IO similar to the S-IOD described in section 3 (Fig. 4a). The SSSa in the central equatorial IO is coherent with the strong equatorial current anomaly, while a significant precipitation anomaly appears in the southeastern IO, about $800 \mathrm{~km}$ to the north of the maximum SSSa (Fig. 4a). The factor dominating the SSSa in the equatorial region is the zonal advection associated with mean SSS gradient and anomalous currents $-u^{\prime} \partial \bar{S} / \partial x$, which is consistent with the result in Zhang et al. (2013). The southward advection is due to the background southeast trade winds, which displace the effect of the precipitation anomaly and thus influence the SSSa at the southern pole. Anomalies of SST and winds indicate that it is a typical IOD mode (Fig. 4b). The mechanism is the same as described in Y. Zhang et al. (2016).

The interannual S-IOD develops quickly from July to December, which is closely related with the strong IOD and thus the internal ocean dynamics and atmospheric forcing in the tropical IO. Since the IOD-related processes are confined north of $10^{\circ} \mathrm{S}$ (Li et al. 2003; Yu et al. 2005; Schott et al. 2009), they cannot explain the SSS signature in the south (Fig. 1). Power spectral analysis reveals that the period of the interannual S-IOD is approximately $5 \mathrm{yr}$, close to the period of ENSO. It suggests that ENSO-related processes contribute to the SSSa signature in the south, consistent with previous studies (Xie et al. 2002; Yu et al. 2005; Schott et al. 2009). Furthermore, interannual climate variability in the Pacific associated with ENSO has been observed to affect upper ocean thermal structure and circulation in the southeastern IO (Feng et al. 2003; Wijffels and Meyers 2004). However, ENSO-induced upper salinity anomalies in the southeastern IO are mostly due to the decadal variations of ENSO, such as the freshening anomalies during extended La Niña events (e.g., Phillips et al. 2005; Feng et al. 2015).

\section{c. Decadal variability and the connection with the western Pacific}

Strong decadal variability is apparent in the time series of the S-IOD index (Fig. 3). The regression of SSSa on the decadal S-IOD index shows a meridional dipole mode within the tropical IO, similar to the interannual S-IOD pattern, but having a high signature in the southern pole. A strong SSSa also appears in the South China Sea (SCS)-Maritime Continent region, connected with the SSSa in the southeastern IO (Fig. 5a). The 2-yr lead regression for precipitation, nearly the same phase as the tendency of SSSa, shows the same pattern as the SSSa, with increased precipitation in the central IO and decreased precipitation in the SCS-Maritime Continent-southeastern IO region (Fig. 5a). This result is consistent with the results of Du et al. (2015), who indicated that significant decadal variability of SSS in the southeastern IO is highly correlated with precipitation, influenced by the decadal modulation of the Walker circulation.

Furthermore, the approximately $10^{\circ}$ latitude displacement of the SSSa and precipitation anomaly in the southeastern IO suggests the contribution of ocean dynamics. The SSSa does not reach maximum under the precipitation maximum at $10^{\circ} \mathrm{S}$, but is shifted to $20^{\circ} \mathrm{S}$.

Further analysis indicates that the SSSa in the southeastern IO is coherent with the SST and SSH anomalies (Figs. 5b,c). There is a northwestern tropical Pacific connection of the SSSa, SSH, and SST 

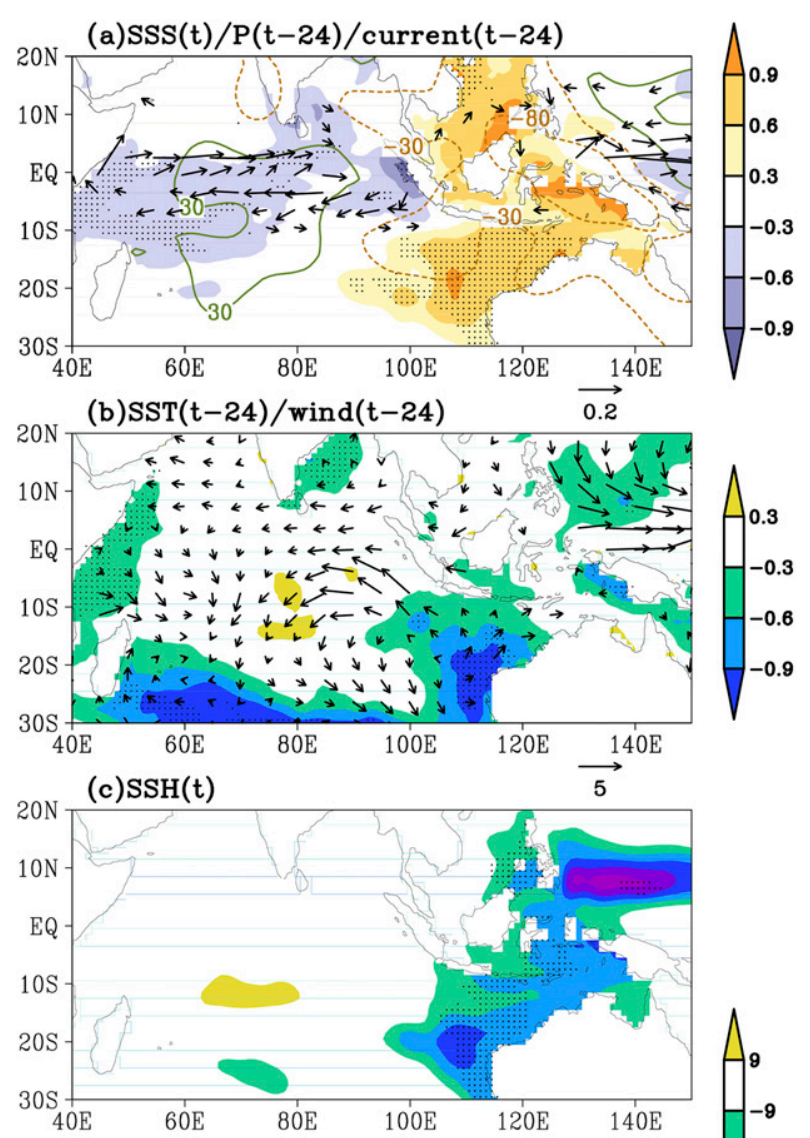

(d) $\mathrm{SSH}(\mathrm{t}-8)$

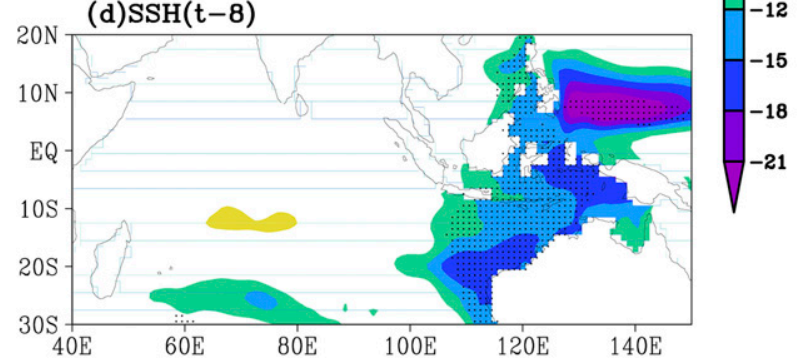

FIG. 5. The regression upon the decadal S-IOD index: (a) SSS (shaded; psu) and 2-yr-lead precipitation (contours; $\mathrm{mm} \mathrm{month}^{-1}$ ) and the currents (vectors; $\mathrm{m} \mathrm{s}^{-1}$ ); (b) 2-yr-lead SST (shaded; ${ }^{\circ} \mathrm{C}$ ) and wind (vectors; $\mathrm{ms}^{-1}$ ); (c) the SSH (shaded; $\mathrm{cm}$ ); and (d) 8-month-lead SSH. An 84-month low-pass filter is applied to all variables. The dotted region indicates that the values are significant at the $90 \%$ confidence level.

anomalies in the southeastern IO. Figure $5 \mathrm{~d}$ shows that the SSSa in the southeastern IO is highly correlated with the SSH anomaly in the northwestern tropical Pacific, and the correlation coefficient is higher than 0.6 when SSH anomalies lead the decadal S-IOD index by nearly 8 months (Fig. 5d). This implies that the ocean dynamic processes from the northwestern tropical Pacific modulate the water mass character in the southeastern IO. Previous studies found that the SSH and thermocline depth anomalies in the northwestern tropical Pacific demonstrate dramatic decadal variability, echoing the basinwide wind forcing in the tropical Pacific, and influence the marginal seas of southeastern Asia and the southeastern IO through the waveguide in the Indonesian Seas (e.g., McDonagh et al. 2005; Nidheesh et al. 2013; Du et al. 2015; Cheng et al. 2016). Planetary wave propagation affects the thermocline depth and meridional current in the southeastern IO, which strengthens or weakens the southward advection of the SSSa signature. In addition, the changes of thermocline may affect the entrainment of salty water from the thermocline into the mixed layer, which favors the maintenance of the SSSa signature. The oceanic signals propagating from the Pacific also affect the decadal variations of the Indonesian Throughflow (e.g., Zhuang et al. 2013; Liu et al. 2015; Vargas-Hernandez et al. 2015), which cause fluctuations of the freshwater transport into the IO and affect the upper ocean salinity budget.

To illustrate the decadal S-IOD, Fig. 6 shows the Hovmöller diagram of the zonally averaged SSS, SSH, precipitation, and SST anomalies within $20^{\circ}$ longitude centered at the northwest-southeast transect connecting the two centers of the decadal S-IOD. The decadal signal of SSSa is slightly stronger in the south than that in the north except for the periods of 1970-80 and 1990-2000 (Fig. 6a). The consistency between SSH and SSS or SST implies that the decadal adjustment of the ocean dynamic processes in the northwestern Pacific and southeastern IO contributes greatly to the decadal S-IOD events. Further, the SSH and thermocline anomalies modulate the upper ocean heat content and the SST, and possibly influence precipitation anomalies (Fig. 6c). Previous studies suggested that the warmer SST in the southeastern IO might drive the regional precipitation anomalies since the late 1990s (e.g., Doi et al. 2015). In this study, the warmer SST off Western Australia seems to attract high precipitation southward during 1995-2001 and 2008-15, which might further favor the freshening of the SSS over the region (Figs. 6b,c). Two significant freshening events were found in this region during 1999-2002 (Phillips et al. 2005) and 2010-11 (Feng et al. 2015).

Figure 7 shows the composites of SSSa during the positive and negative phases of decadal S-IOD index and the forcing field in the developing and decay phases. Precipitation explains the major part of the SSSa pattern, despite a spatial shift in the high value center. The opposite phase change of the precipitation between the central tropical IO and the SCS-Maritime Continent-southeastern IO region is coherent with the equatorial zonal wind anomaly, implying the dominant 
(a)SSS \& SSH

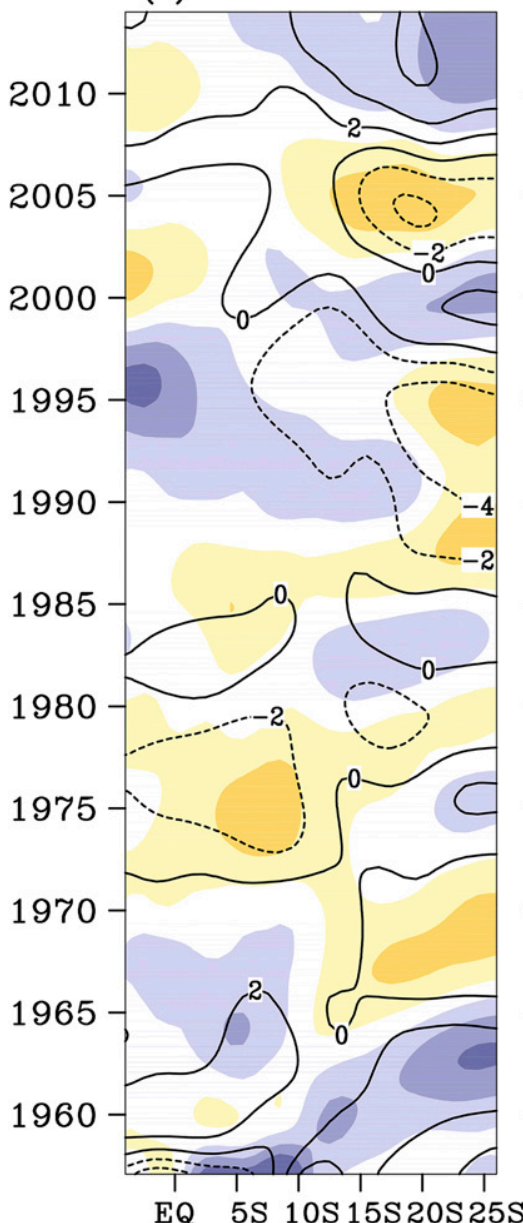

EQ 5S 10S 15S20S25S
(b)SSS \& $P$
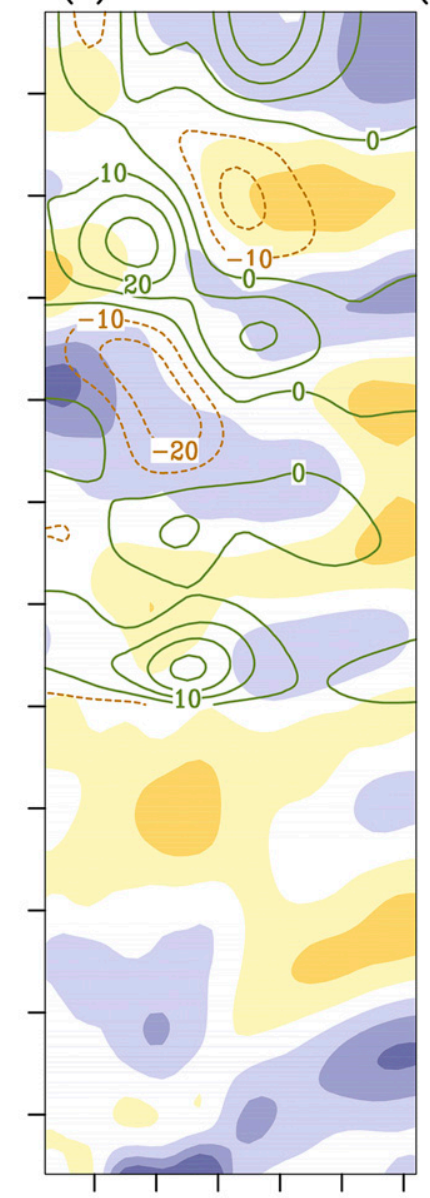

EQ $5 \mathrm{~S} 10 \mathrm{~S} 15 \mathrm{~S} 20 \mathrm{~S} 25 \mathrm{~S}$
(c)SST \& $\mathrm{P}$

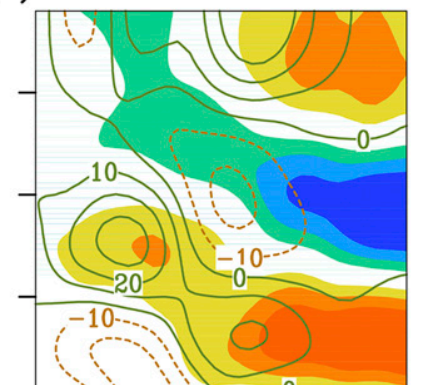

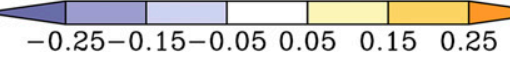

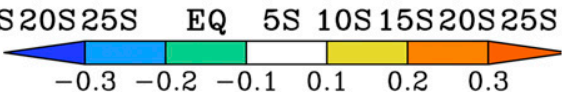

FIG. 6. Hovmöller diagrams of the zonally averaged decadal anomalies within $20^{\circ}$ longitude centered at the northwest-southeast transect marked in Fig. 1a: (a) SSS (shaded; psu) and SSH (contours; cm); (b) SSS (shaded; psu) and $P$ (contours; mm month ${ }^{-1}$ ); and (c) SST (shaded; ${ }^{\circ} \mathrm{C}$ ) and $P$ (contours; mm month ${ }^{-1}$ ). The GPCP precipitation spans from 1979 to 2014.

role of decadal adjustment of the Walker circulation in the IO and Maritime Continent, as indicated by previous studies (e.g., Wang and Mehta 2008; Han et al. 2014; Du et al. 2015). The composite of SSH anomaly, leading the S-IOD index by 8 months, shows the northwestern Pacific playing an important role in the SSSa in the southeastern IO, consistent with the regression results.

Mixed layer salinity budget analysis further shows the relative contributions from the precipitation and ocean dynamics (Fig. 8). In the northern pole, both precipitation and ocean advection (Fig. 8), especially the zonal advection, dominate the SSSa (Fig. 9). The zonal advection associated with mean SSS gradient and anomalous currents $-u^{\prime} \partial \bar{S} / \partial x$, forced by equatorial wind anomaly, contributes to the major part of the zonal advection (Figs. 10c,g). The ocean advection caused the SSSa in the northern pole to play an important role for both the interannual and the decadal time scales, which are mainly associated with the equatorial current anomalies. Furthermore, the contribution of precipitation to the SSSa in the northern pole is only significant on the decadal time scale.

In the southern pole, the ocean advection redistributes the contribution by the precipitation and strengthens the SSSa signature (Fig. 8). The SSSa signature, originating from the anomalous precipitation in the SCS and Maritime Continent, is advected into the southeastern IO and strengthened by local precipitation (Figs. 8c,f). The Indonesian Throughflow then advects the SSS signature into the southeastern 
(a)S-IOD index

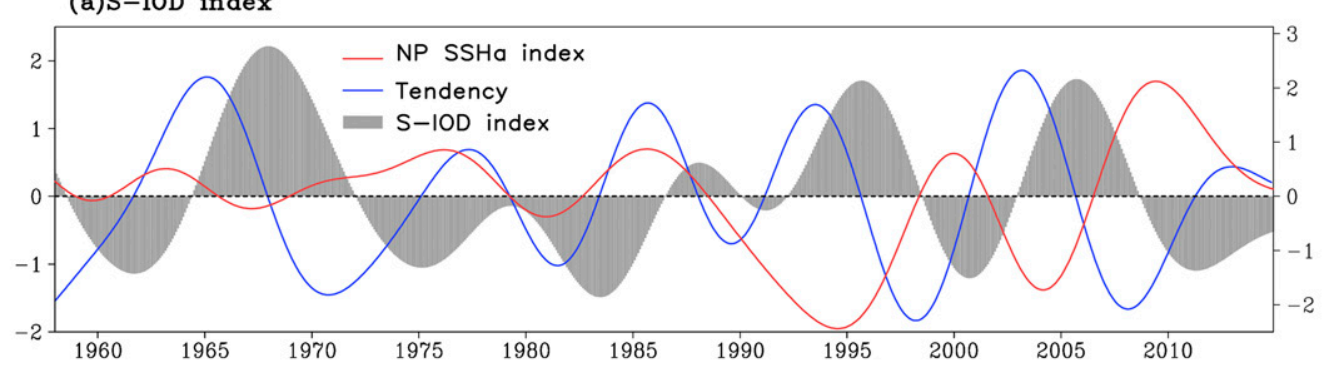

Positive

Negative
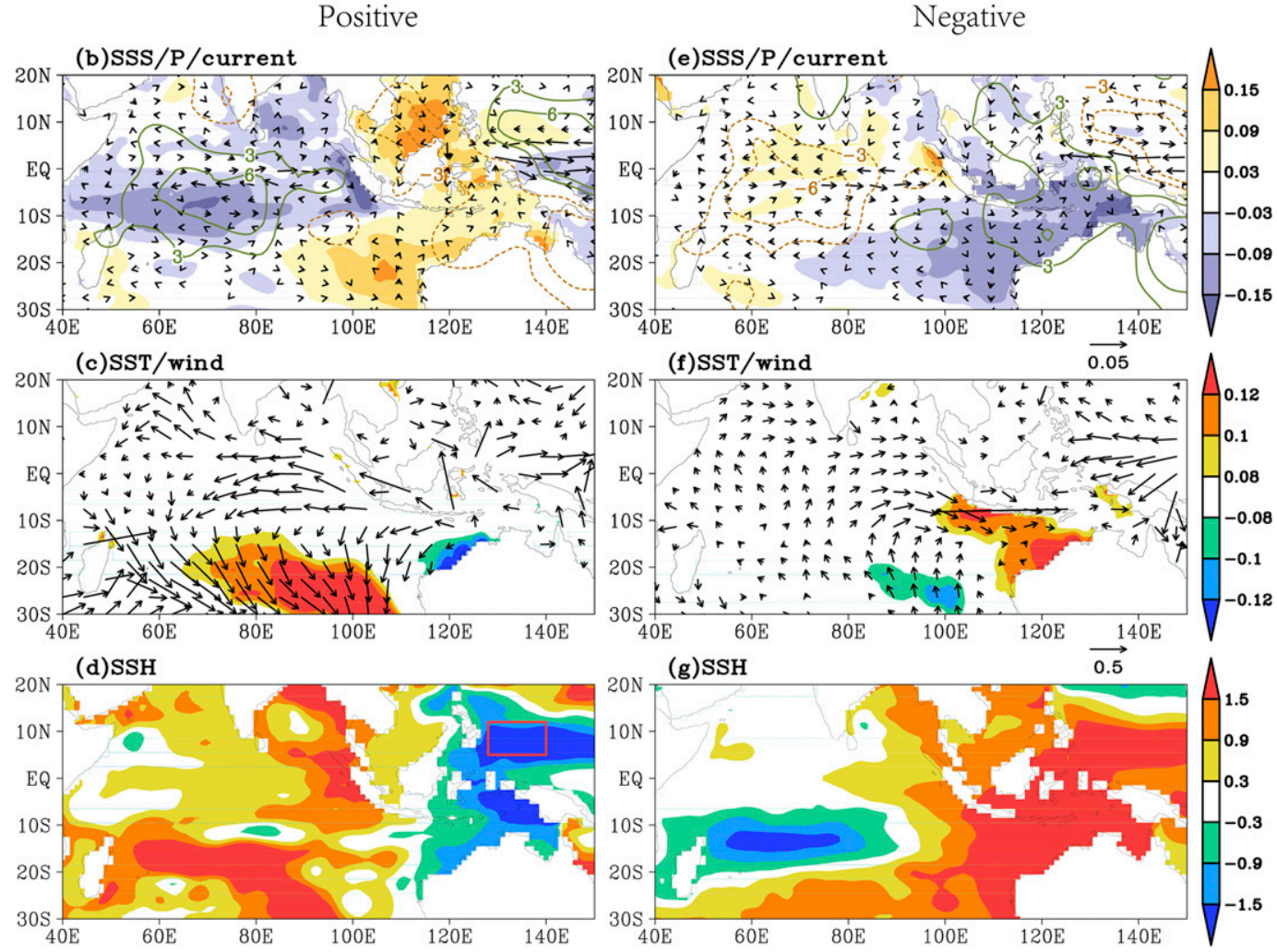

FIG. 7. Composite of anomalous fields during positive and negative phase of decadal S-IOD: (a) the normalized S-IOD index and its tendency, superimposed with the index of SSH anomaly in the northwestern Pacific; (b), (e) SSS (shaded; psu), precipitation (contours; $\mathrm{mm} \mathrm{month}^{-1}$ ), and the currents (vectors; $\mathrm{m} \mathrm{s}^{-1}$ ); (c),(f) SST (shaded; ${ }^{\circ} \mathrm{C}$ ) and wind (vectors; $\mathrm{m} \mathrm{s}^{-1}$ ); and (d), (g) SSH (shaded; $\mathrm{cm}$ ). The SSSa is averaged in two groups, with the decadal S-IOD index larger or smaller than zero, corresponding to the positive and negative phases, respectively. The SSH and SST, precipitation, currents, and wind anomalies are handled in same way, but the phase of SSH leads by 8 months and the others are based on the tendency of decadal S-IOD index. The red rectangle in (d) shows the average region for the SSH anomaly in the northwestern Pacific.

IO within a narrow band around $10^{\circ} \mathrm{S}$ (Figs. 9a,c and 10a,e). The Ekman transport, due to the background southeast trade winds, advects the anomalous SSS signature from north of $12^{\circ} \mathrm{S}$ to about $20^{\circ} \mathrm{S}$ with the largest contribution along the axis of the trade winds at $20^{\circ} \mathrm{S}$ and off the northwestern Australia coast (Figs. 9b,d and 10b,f). Meanwhile, the meridional advection associated with mean SSS gradient and anomalous currents $-v^{\prime} \partial \bar{S} / \partial y$, caused by zonal gradient of SSH, strengthens the southward advection of SSSa and extends the signature to south of $25^{\circ} \mathrm{S}$ along the west coast of Australia (Figs. 9b,d and 10d,h). The large meridional gradient of mean SSS between $15^{\circ}$ and $28^{\circ} \mathrm{S}$ dominates the meridional advection (Figs. 10d,h), even though the current anomaly is small there (Figs. 7b,e). The strong SSS front between the freshwater from the outflow of the Indonesian Throughflow and the eastern equatorial IO and the salty water from the subtropical convergence 
Positive
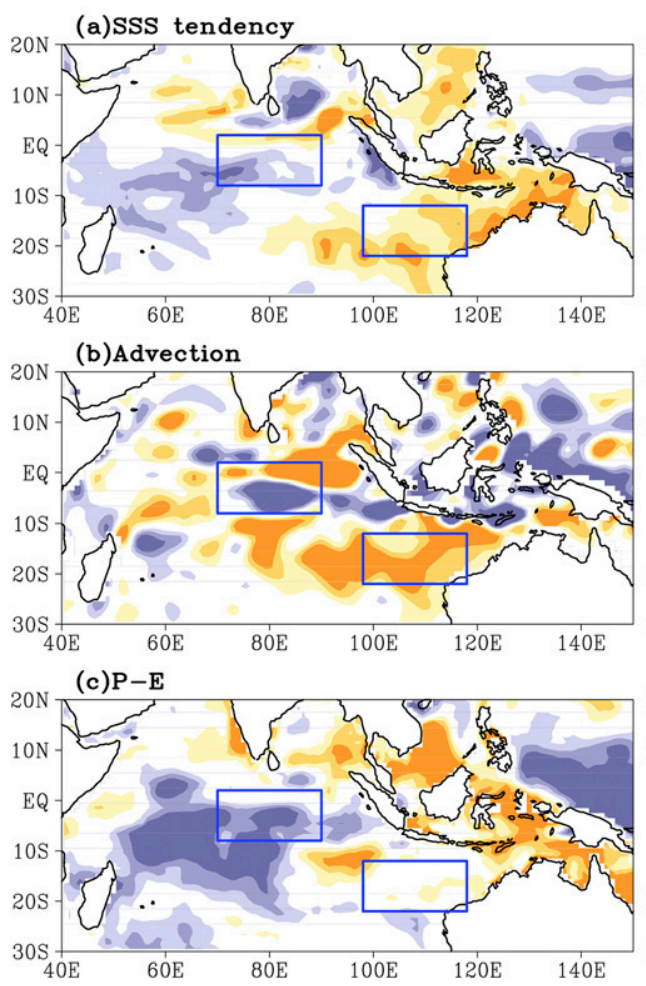

Negative
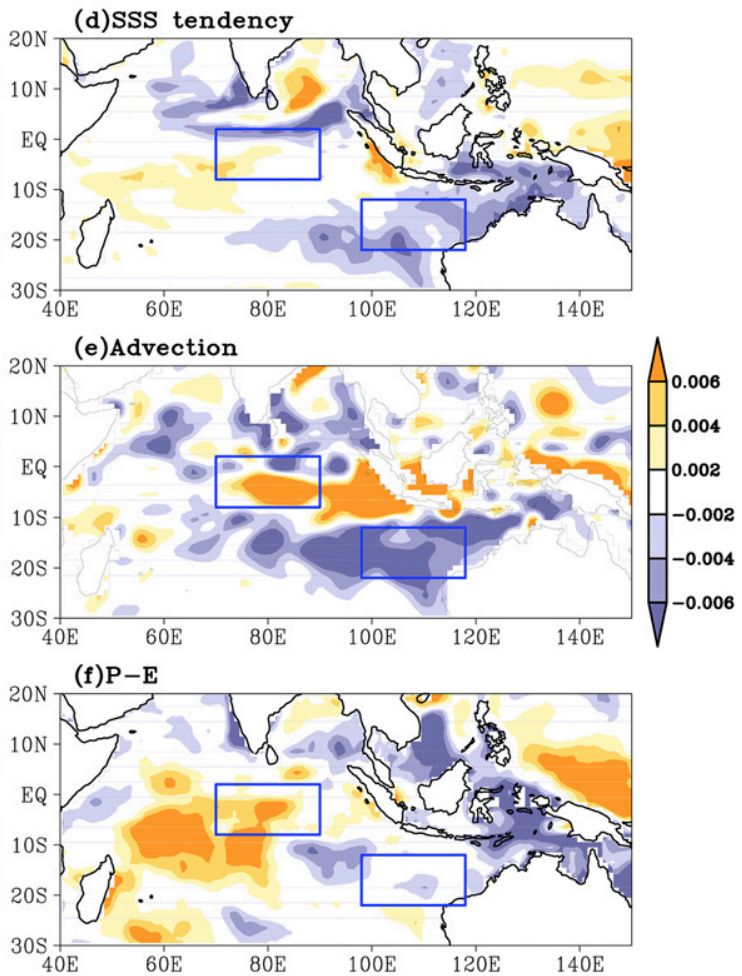

FIG. 8. Composite of the main terms in the mixed layer salinity budget during positive and negative phase of the tendency of decadal S-IOD index (psu month ${ }^{-1}$ ): (a),(d) salinity tendency, (b),(e) ocean advection, and (c),(f) freshwater flux $(P-E)$. Blue rectangles indicate the two poles of S-IOD.

zone explain the large mean SSS gradient. Without a vertical velocity dataset, it is difficult to estimate the contribution from the entrainment/detrainment. However, as shown in Figs. 7d,g, the SSH anomaly highly corresponds to the SSSa in the southeastern IO. The changes of the thermocline may contribute to the maintenance of the SSSa signature in the southern pole.
Positive

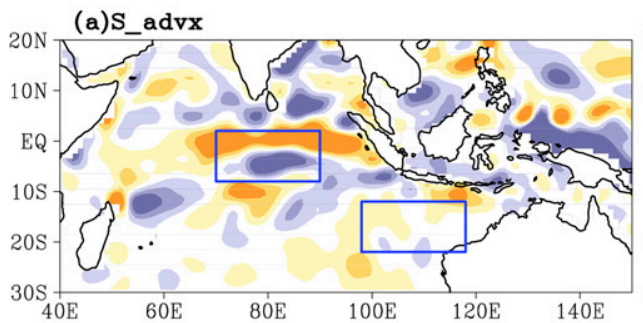

(b)S_advy

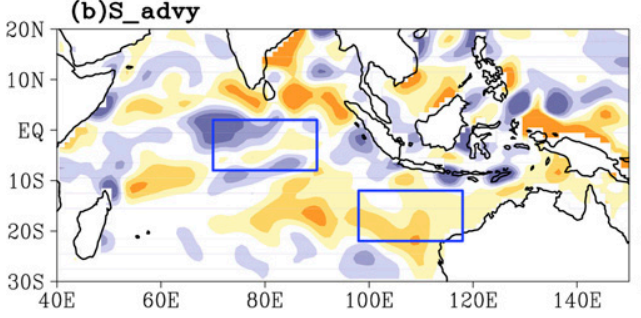

Negative

(c)S_advx

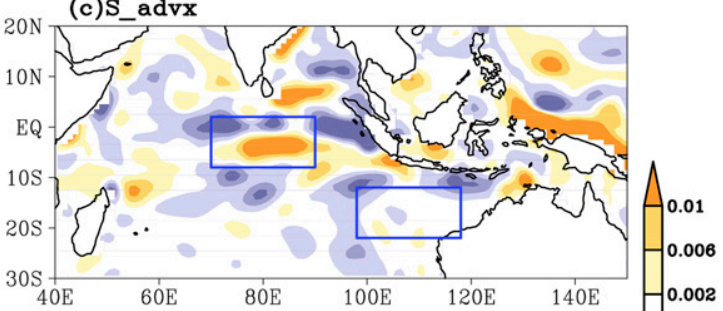

(d) S advy

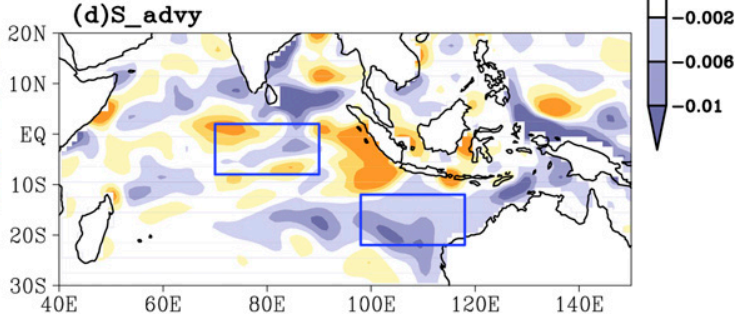

FIG. 9. Composite of the zonal and meridional advection during positive and negative phase of the tendency of decadal S-IOD index (psu month ${ }^{-1}$ ): (a),(c) zonal and (b),(d) meridional advection. 

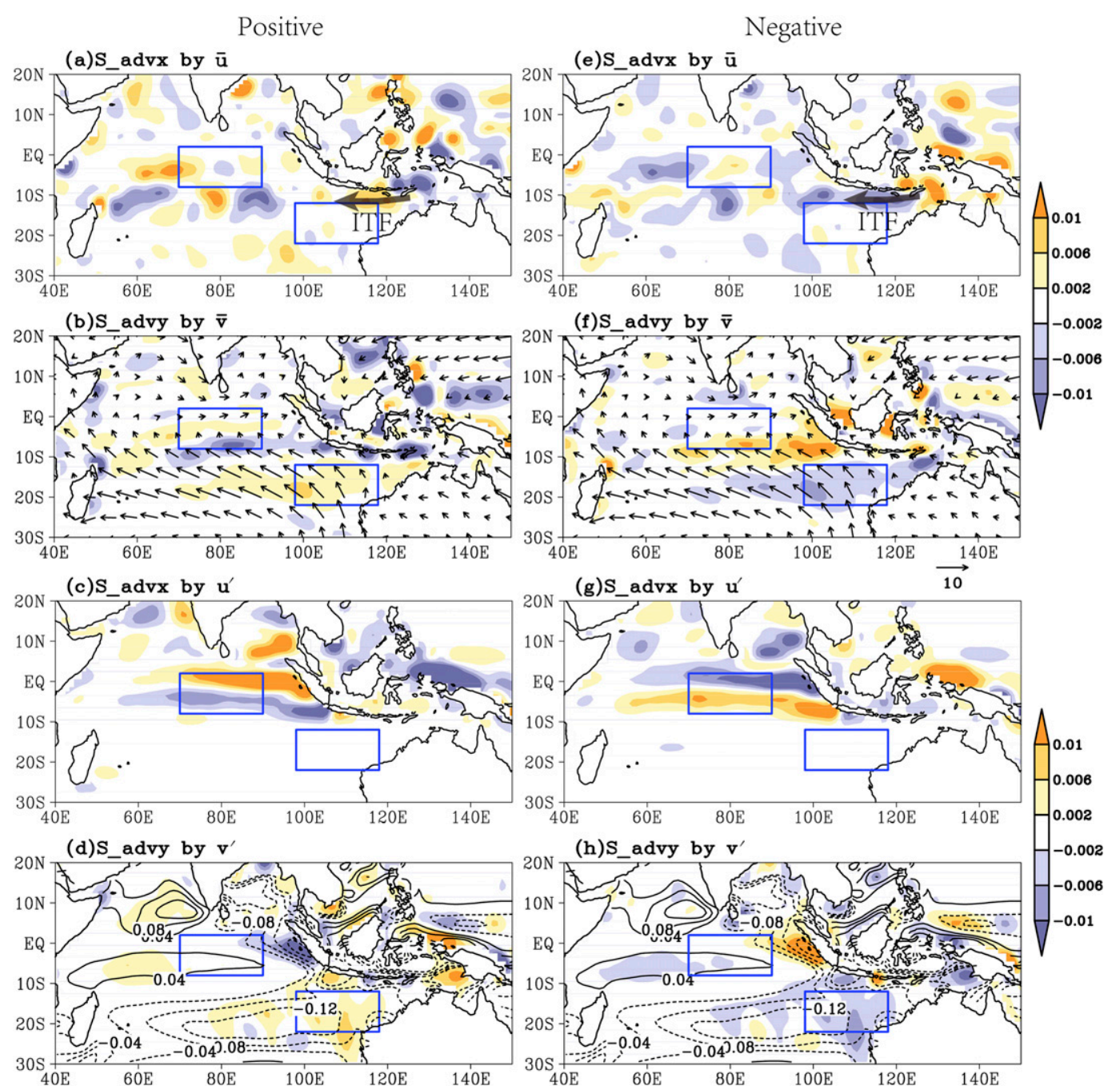

FIG. 10. Decomposition of the zonal and meridional advection during positive and negative phases of the tendency of decadal S-IOD index (psu month ${ }^{-1}$ ): (a),(e) zonal advection of anomalous SSS as a result of the mean currents $-\bar{u} \partial S^{\prime} / \partial x$; (c),(g) zonal advection associated with mean SSS gradient and anomalous currents $-u^{\prime} \partial \bar{S} / \partial x$; and (b),(f) and (d),(h) as in (a),(e) and (c),(g), respectively, but for meridional advection. The annual mean wind (vectors; $\mathrm{m} \mathrm{s}^{-1}$ ) is superimposed in (b) and (f). Meridional gradient of mean SSS (contours; psu) is superimposed in (d) and (h).

\section{Discussion}

As indicated by previous studies, the changes of the thickness of the barrier layer in the southeastern IO could contribute to the salinity balance on seasonal and interannual time scales (Qu and Meyers 2005; Grunseich et al. 2011; N. Zhang et al. 2016). On the decadal time scale, the thermocline shoals (deepens) in the southeastern IO during the positive (negative) phase of S-IOD, which is modulated by the ocean dynamics in the northwestern Pacific (Figs. 11a,d). The mixed layer shoals with the thermocline during the positive phase (Figs. 11a,b). However, during the negative phase, near-surface salinity stratification strengthens when the thermocline deepens
(Figs. 11d,e). A barrier layer forms and impedes the entrainment of salty thermocline water into the mixed layer (Sprintall and Tomczak 1992; Vialard and Delecluse 1998). The thickness of the barrier layer weakens or changes little during the positive phase and strengthens during the negative phase, which provides a favorable background for the maintenance of the SSSa signature in the southern pole.

Figure 12 illustrates the modulation of the SSH and thermocline on the SST and SSS and the main processes related with decadal S-IOD along the meridional track shown in Fig. 1, in particular for negative events. In the north, the positive SSSa is dominated by decreased precipitation and zonal advection, which is associated 
Positive

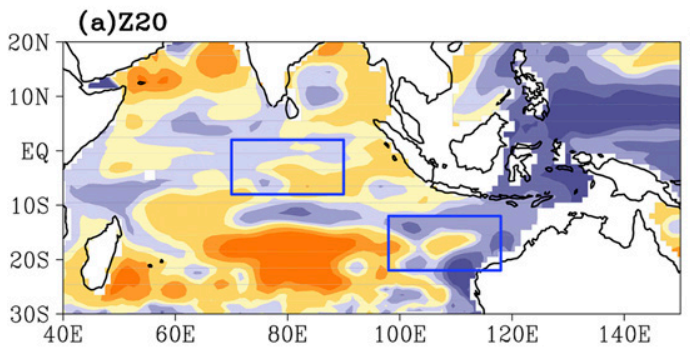

(b) MLD

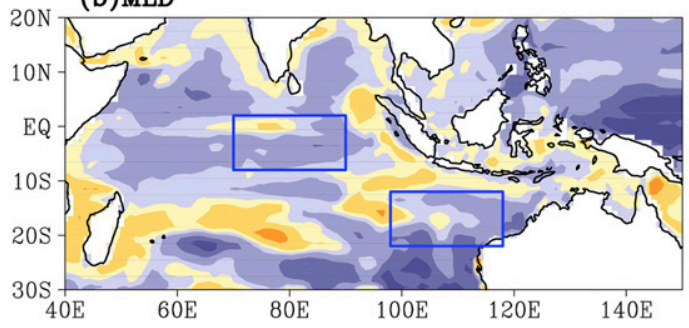

(c)BLT
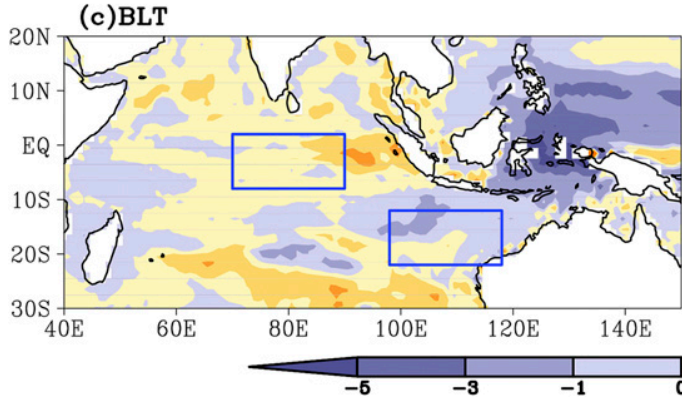

FIG. 11. Composite of (a),(d) the $20^{\circ} \mathrm{C}$ isothermal layer depth (Z20), (b),(e) the mixed layer depth, and (c),(f) the barrier layer thickness anomalies during positive and negative phase of the decadal S-IOD $(\mathrm{m})$. The anomalies are handled in same way as the SSH anomaly in Fig. 7.

with changes of the Walker circulation (Du et al. 2015). In the south, the ocean dynamic adjustments in the northwestern Pacific modulate the upper ocean thermohaline structure in the southeastern IO, depressing the mixing of salty water below the surface layer and contributing to the advection of the surface warm and freshwater. Precipitation further contributes to the development of the decadal S-IOD. Both the regional airsea exchanges and the remote oceanic processes are virtually in phase on decadal time scales, with SSSa in the southeastern IO lagging the SSH anomaly in the northwestern tropical Pacific by 8 months, reflecting the processes of planetary wave propagation.

The above analysis suggests that the atmospheric forcing and the ocean dynamics during the negative events are mostly opposite to those during the positive events. However, the intensities of SSSa and the associated processes vary with decades (Fig. 6). Asymmetries do exist between the positive and negative events (e.g., the precipitation feedback to SSSa only happens during negative events) and need further investigation in the future.

\section{Summary}

This study uses ORAS4 and observations to analyze the SSS variability in the IO during 1958-2014. The results indicate that the S-IOD is a dominant mode of SSS

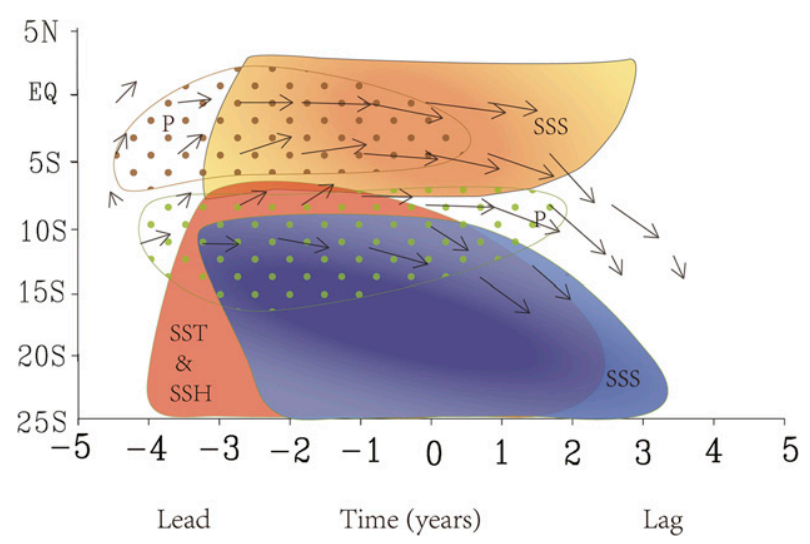

FIG. 12. The evolution and the meridional location of the SSSa during negative decadal S-IOD and the relative key processes. 


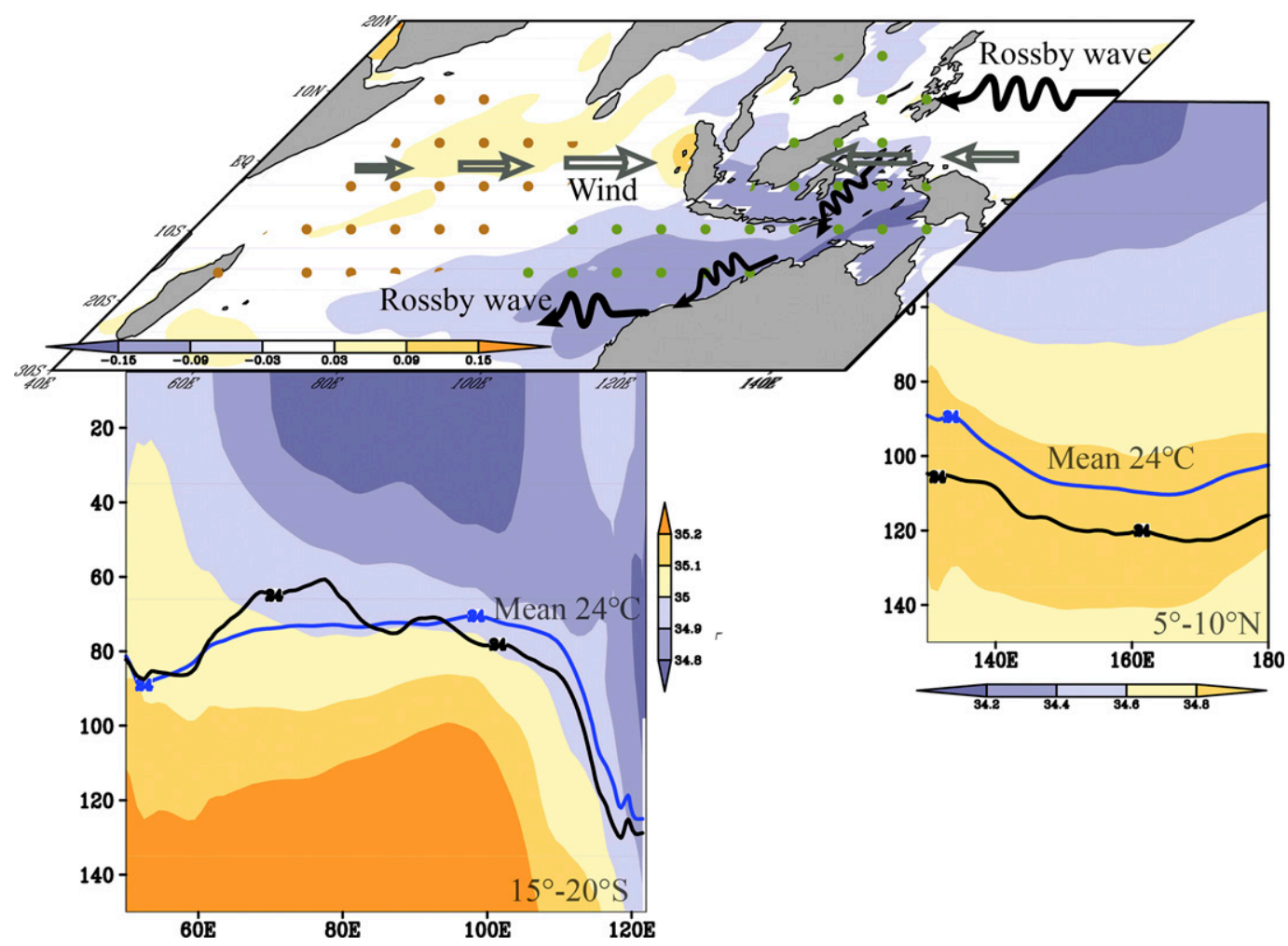

FIG. 13. Schematic diagrams of the processes explaining the development of the negative decadal S-IOD. (top) The horizontal background map (shadings) uses the composite of SSSa during negative phase of decadal S-IOD index, with needed smoothing for better illustration. Dots indicate the precipitation anomaly (green, $P>3 \mathrm{~mm} \mathrm{month}^{-1}$, and brown, $P<3 \mathrm{~mm} \mathrm{month}^{-1}$ ). (bottom) The transect background maps are the mean salinity. The $24^{\circ} \mathrm{C}$ isotherm (black curve) is for the negative decadal S-IOD composite. The mean $24^{\circ} \mathrm{C}$ isotherm (blue curve) is averaging for 1958-2014.

variability in the tropical IO, with contrasting SSSa signatures in the equatorial and southeastern IO. The SIOD index shows multiple time scale variability: a longterm linear trend, decadal variability, and interannual variability.

The interannual S-IOD events concur with strong IOD and ENSO events. Consistent with the results from short time observations (Y. Zhang et al. 2016), the anomalous ocean advection driven by the equatorial wind dominates the strong SSS variability in the northern pole, while the precipitation anomaly associated with preceding SST anomaly contributes to the much weaker SSS signature in the southern pole.

The decadal S-IOD variability shows different features from the interannual event. First, the SSS signature is slightly stronger in the southern pole than that in the northern pole during most of the decades except the 1970-80 and 1990-2000. At the northern pole, the SSSa is forced by precipitation forcing and ocean advection driven by equatorial wind, which is associated with variations of Walker circulation. Second, the SSSa caused by the precipitation anomaly in the Maritime
Continent is carried by the Indonesian Throughflow into the southeastern IO along $10^{\circ} \mathrm{S}$, which is then enhanced by local precipitation in the southeastern IO and then advected southward by Ekman transport caused by the background southeast trade winds. Furthermore, remote ocean dynamic processes in the northwestern Pacific influence the SSSa in the southern pole through the Indonesian Seas, which reflects the climate effects for the decadal adjustment of the air-sea system in the Indo-Pacific. A schematic diagram (Fig. 13) illustrates this process. As Pacific wind force accumulates an abnormal SSH or thermocline anomaly through Rossby wave dynamics in the northwestern Pacific, part of the SSH-thermocline signature is transmitted through the Indonesian Seas in the form of planetary waves. Off Western Australia, a deepening or shoaling SSH or thermocline corresponds to the strengthening or weakening of surface freshwater advection, and may depress or promote the entrainment of the salty water from the thermocline into the mixed layer. A deep thermocline favors the maintenance of freshwater at the surface layer, and vice versa. 
Acknowledgments. We thank Prof. Y. Masumoto and two anonymous reviewers for their comments and suggestions that helped improve the manuscript. We acknowledge ECMWF for providing the ORAS4 data (https://www.ecmwf.int/en/research/climate-reanalysis/oceanreanalysis). The CCMP wind data are available from the RSS (http://www.remss.com/measurements/ccmp/). The GPCP precipitation was obtained from NASA GSFC (http://precip. gsfc.nasa.gov). The OAFlux data were provided by WHOI OAFlux project of Woods Hole Oceanographic Institution (http://oaflux.whoi.edu). The ERSST data were provided by NOAA's National Climate Data Center (https://www.ncdc. noaa.gov/data-access/marineocean-data/extendedreconstructed-sea-surface-temperature-ersst). This work is supported by the National Natural Science Foundation of China (41506019 and 41525019), the State Oceanic Administration of China (GASI-IPOVAI-02), the Open Project Program of State Key Laboratory of Tropical Oceanography (Grant LTOZZ1501), and the CAS/ SAFEA International Partnership Program for Creative Research Teams. CSHOR is a joint research Centre for Southern Hemisphere Ocean Research between QNLM and CSIRO.

\section{REFERENCES}

Adler, R. F., and Coauthors, 2003: The version-2 Global Precipitation Climatology Project (GPCP) monthly precipitation analysis (1979-present). J. Hydrometeor., 4, 1147-1167, https://doi.org/10.1175/1525-7541(2003)004<1147: TVGPCP $>2.0 . C O ; 2$.

Antonov, J. I., S. Levitus, and T. P. Boyer, 2002: Steric sea level variations during 1957-1994: Importance of salinity. J. Geophys. Res., 107, 8013, https://doi.org/10.1029/2001JC000964.

Atlas, R., R. N. Hoffman, J. Ardizzone, S. M. Leidner, J. C. Jusem, D. K. Smith, and D. Gombos, 2011: A cross-calibrated, multiplatform ocean surface wind velocity product for meteorological and oceanographic applications. Bull. Amer. Meteor. Soc., 92, 157-174, https://doi.org/10.1175/2010BAMS2946.1.

Balmaseda, M. A., K. Mogensen, and A. T. Weaver, 2013: Evaluation of the ECMWF ocean reanalysis system ORAS4. Quart. J. Roy. Meteor. Soc., 139, 1132-1161, https://doi.org/10.1002/ qj.2063.

Boyer, T. P., S. Levitus, J. I. Antonov, R. A. Locarnini, and H. E. Garcia, 2005: Linear trends in salinity for the World Ocean, 1955-1998. Geophys. Res. Lett., 32, L01604, https://doi.org/ 10.1029/2004GL021791.

Bretherton, C. S., M. Widmann, V. P. Dymnikov, J. M. Wallace, and I. Bladé, 1999: The effective number of spatial degrees of freedom of a time-varying field. J. Climate, 12, 1990-2009, https://doi.org/10.1175/1520-0442(1999)012<1990: TENOSD $>2.0 . \mathrm{CO} ; 2$.

Cheng, X., S.-P. Xie, Y. Du, J. Wang, X. Chen, and J. Wang, 2016: Interannual-to-decadal variability and trends of sea level in the South China Sea. Climate Dyn., 46, 3113-3126, https://doi.org/ 10.1007/s00382-015-2756-1.

Curry, R., B. Dickson, and I. Yashayaev, 2003: A change in the freshwater balance of the Atlantic Ocean over the past four decades. Nature, 426, 826-829, https://doi.org/10.1038/ nature 02206.

Dee, D. P., and Coauthors, 2011: The ERA-Interim reanalysis: Configuration and performance of the data assimilation system. Quart. J. Roy. Meteor. Soc., 137, 553-597, https://doi.org/ 10.1002/qj.828.

Delcroix, T., and M. J. McPhaden, 2002: Interannual sea surface salinity and temperature changes in the western Pacific warm pool during 1992-2000. J. Geophys. Res., 107, 8002, https://doi.org/10.1029/2001JC000862.

Doi, T., S. K. Behera, and T. Yamagata, 2015: An interdecadal regime shift in rainfall predictability related to the Ningaloo Niño in the late 1990s. J. Geophys. Res. Oceans, 120, 13881396, https://doi.org/10.1002/2014JC010562.

Du, Y., and Y. Zhang, 2015: Satellite and Argo observed surface salinity variations in the tropical Indian Ocean and their association with the Indian Ocean dipole mode. J. Climate, 28, 695-713, https://doi.org/10.1175/JCLI-D-14-00435.1.

,-- M. Feng, T. Wang, N. Zhang, and S. Wijffels, 2015: Decadal trends of the upper ocean salinity in the tropical IndoPacific since mid-1990s. Sci. Rep., 5, 16050, https://doi.org/ 10.1038/srep16050.

Durack, P. J., and S. E. Wijffels, 2010: Fifty-year trends in global ocean salinities and their relationship to broad-scale warming. J. Climate, 23, 4342-4362, https://doi.org/10.1175/ 2010JCLI3377.1.

_ — - and R. J. Matear, 2012: Ocean salinities reveal strong global water cycle intensification during 1950 to 2000. Science, 336, 455-458, https://doi.org/10.1126/science.1212222.

Durand, F., G. Alory, R. Dussin, and N. Reul, 2013: SMOS reveals the signature of Indian Ocean dipole events. Ocean Dyn., 63, 1203-1212, https://doi.org/10.1007/s10236-013-0660-y.

Feng, M., P. Hacker, and R. Lukas, 1998: Upper ocean heat and salt balances in response to a westerly wind burst in the western equatorial Pacific during TOGA COARE. J. Geophys. Res., 103, 10 289-10311, https://doi.org/10.1029/97JC03286.

, G. Meyers, A. Pearce, and S. Wijffels, 2003: Annual and interannual variations of the Leeuwin Current at $32^{\circ} \mathrm{S}$. J. Geophys. Res., 108, 3355, https://doi.org/10.1029/2002JC001763.

_ J. Benthuysen, N. Zhang, and D. Slawinski, 2015: Freshening anomalies in the Indonesian Throughflow and impacts on the Leeuwin Current during 2010-2011. Geophys. Res. Lett., 42, 8555-8562, https://doi.org/10.1002/2015GL065848.

Grunseich, G., B. Subrahmanyam, V. S. N. Murty, and B. S. Giese, 2011: Sea surface salinity variability during the Indian Ocean dipole and ENSO events in the tropical Indian Ocean. J. Geophys. Res., 116, C11013, https://doi.org/10.1029/ 2011JC007456.

Han, W., J. Vialard, M. J. McPhaden, T. Lee, Y. Masumoto, M. Feng, and W. P. M. de Ruijter, 2014: Indian Ocean decadal variability: A review. Bull. Amer. Meteor. Soc., 95, 1679-1703, https://doi.org/10.1175/BAMS-D-13-00028.1.

Huffman, G. J., R. F. Adler, D. T. Bolvin, and G. Gu, 2009: Improving the global precipitation record: GPCP version 2.1. Geophys. Res. Lett., 36, L17808, https://doi.org/10.1029/ 2009GL040000.

Kara, A. B., P. A. Rochford, and H. E. Hurlburt, 2000: An optimal definition for ocean mixed layer depth. J. Geophys. Res., 105, 16 803-16 821, https://doi.org/10.1029/2000JC900072.

Li, T., B. Wang, C.-P. Chang, and Y. Zhang, 2003: A theory for the Indian Ocean dipole-zonal mode. J. Atmos. Sci., 60, 2119-2135, https://doi.org/10.1175/1520-0469(2003)060<2119: ATFTIO $>2.0 . \mathrm{CO} ; 2$ 
Liu, Q.-Y., M. Feng, D. Wang, and S. Wijffels, 2015: Interannual variability of the Indonesian Throughflow transport: A revisit based on 30 year expendable bathythermograph data. J. Geophys. Res. Oceans, 120, 8270-8282, https://doi.org/ 10.1002/2015JC011351.

Masson, S., J.-P. Boulanger, C. Menkes, P. Delecluse, and T. Yamagata, 2004: Impact of salinity on the 1997 Indian Ocean dipole event in a numerical experiment. J. Geophys. Res., 109, C02002, https://doi.org/10.1029/2003JC001807.

McDonagh, E. L., H. L. Bryden, B. A. King, R. J. Sanders, S. A. Cunningham, and R. Marsh, 2005: Decadal changes in the south Indian Ocean thermocline. J. Climate, 18, 1575-1590, https://doi.org/10.1175/JCLI3350.1.

Nidheesh, A. G., M. Lengaigne, J. Vialard, A. S. Unnikrishnan, and H. Dayan, 2013: Decadal and long-term sea level variability in the tropical Indo-Pacific Ocean. Climate Dyn., 41, 381-402, https://doi.org/10.1007/s00382-012-1463-4.

Nyadjro, E. S., and B. Subrahmanyam, 2014: SMOS mission reveals the salinity structure of the Indian Ocean dipole. IEEE Geosci. Remote Sens. Lett., 11, 1564-1568, https://doi.org/10.1109/ LGRS.2014.2301594.

Phillips, H. E., S. E. Wijffels, and M. Feng, 2005: Interannual variability in the freshwater content of the Indonesian-Australian basin. Geophys. Res. Lett., 32, L03603, https://doi.org/10.1029/ 2004GL021755.

Qu, T., and G. Meyers, 2005: Seasonal variation of barrier layer in the southeastern tropical Indian Ocean. J. Geophys. Res., 110, C11003, https://doi.org/10.1029/2004JC002816.

—, and J.-Y. Yu, 2014: ENSO indices from sea surface salinity observed by Aquarius and Argo. J. Oceanogr., 70, 367-375, https://doi.org/10.1007/s10872-014-0238-4.

_, Y. T. Song, and C. Maes, 2014: Sea surface salinity and barrier layer variability in the equatorial Pacific as seen from Aquarius and Argo. J. Geophys. Res. Oceans, 119, 15-29, https://doi.org/10.1002/2013JC009375.

Reynolds, R. W., N. A. Rayner, T. M. Smith, D. C. Stokes, and W. Wang, 2002: An improved in situ and satellite SST analysis for climate. J. Climate, 15, 1609-1625, https://doi.org/10.1175/ 1520-0442(2002)015<1609:AIISAS > 2.0.CO;2.

Saji, N. H., B. N. Goswami, P. N. Vinayachandran, and T. Yamagata, 1999: A dipole mode in the tropical Indian Ocean. Nature, 401, 360-363.

Schott, F. A., S.-P. Xie, and J. P. McCreary Jr., 2009: Indian Ocean circulation and climate variability. Rev. Geophys., 47, RG1002, https://doi.org/10.1029/2007RG000245.

Singh, A., T. Delcroix, and S. Cravatte, 2011: Contrasting the flavors of El Niño-Southern Oscillation using sea surface salinity observations. J. Geophys. Res., 116, C06016, https://doi.org/ 10.1029/2010JC006862.

Sprintall, J., and M. Tomczak, 1992: Evidence of the barrier layer in the surface layer of the tropics. J. Geophys. Res., 97, 73057316, https://doi.org/10.1029/92JC00407.

Stark, J. D., C. J. Donlon, M. J. Martin, and M. E. McCulloch, 2007: OSTIA: An operational, high resolution, real time, global sea surface temperature analysis system. Proc. OCEANS 2007-Europe, Aberdeen, Scotland, IEEE, 061214-029, https:// doi.org/10.1109/OCEANSE.2007.4302251.

Subrahmanyam, B., V. S. N. Murty, and D. M. Heffner, 2011: Sea surface salinity variability in the tropical Indian Ocean. $R e$ mote Sens. Environ., 115, 944-956, https://doi.org/10.1016/ j.rse.2010.12.004.
Thompson, B., C. Gnanaseelan, and P. S. Salvekar, 2006: Variability in the Indian Ocean circulation and salinity and its impact on SST anomalies during dipole events. J. Mar. Res., 64, 853-880, https://doi.org/10.1357/002224006779698350.

Uppala, S. M., and Coauthors, 2005: The ERA-40 Re-Analysis. Quart. J. Roy. Meteor. Soc., 131, 2961-3012, https://doi.org/ 10.1256/qj.04.176.

Vargas-Hernandez, J. M., S. Wijffels, G. Meyers, and N. J. Holbrook, 2015: Slow westward movement of salinity anomalies across the tropical south Indian Ocean. J. Geophys. Res. Oceans, 120, 5436-5456, https://doi.org/10.1002/2015JC010933.

Vialard, J., and P. Delecluse, 1998: An OGCM study for the TOGA decade. Part II: Barrier-layer formation and variability. J. Phys. Oceanogr., 28, 1089-1106, https://doi.org/10.1175/ 1520-0485(1998)028<1089:AOSFTT>2.0.CO;2.

Vinayachandran, P. N., and R. S. Nanjundiah, 2009: Indian Ocean sea surface salinity variations in a coupled model. Climate Dyn., 33, 245-263, https://doi.org/10.1007/s00382-008-0511-6.

Wang, H., and V. M. Mehta, 2008: Decadal variability of the IndoPacific warm pool and its association with atmospheric and oceanic variability in the NCEP-NCAR and SODA reanalyses. J. Climate, 21, 5545-5565, https://doi.org/10.1175/ 2008JCLI2049.1.

Wentz, F. J., J. Scott, R. Hoffman, M. Leidner, R. Atlas, and J. Ardizzone, 2015: Remote Sensing Systems Cross-Calibrated Multi-Platform (CCMP) 6-hourly ocean vector wind analysis product on $0.25 \mathrm{deg}$ grid, version 2.0. Remote Sensing Systems, accessed 9 May 2016, www.remss.com/measurements/ ccmp.

Wijffels, S., and G. Meyers, 2004: An intersection of oceanic waveguides: Variability in the Indonesian Throughflow region. J. Phys. Oceanogr., 34, 1232-1253, https://doi.org/ 10.1175/1520-0485(2004)034<1232:AIOOWV>2.0.CO;2.

Xie, S.-P., H. Annamalai, F. A. Schott, and J. P. McCreary Jr., 2002: Structure and mechanism of south Indian Ocean climate variability. J. Climate, 15, 864-878, https://doi.org/10.1175/ 1520-0442(2002)015,0864:SAMOSI.2.0.CO;2.

Yu, L., and R. A. Weller, 2007: Objectively analyzed air-sea heat fluxes for the global ice-free oceans (1981-2005). Bull. Amer. Meteor. Soc., 88, 527-539, https://doi.org/10.1175/ BAMS-88-4-527.

Yu, W., B. Xiang, L. Liu, and N. Liu, 2005: Understanding the origins of interannual thermocline variations in the tropical Indian Ocean. Geophys. Res. Lett., 32, L24706, https://doi.org/ 10.1029/2005GL024327.

Zhang, N., M. Feng, Y. Du, J. Lan, and S. E. Wijffels, 2016: Seasonal and interannual variations of mixed layer salinity in the southeast tropical Indian Ocean. J. Geophys. Res. Oceans, 121, 4716-4731, https://doi.org/10.1002/2016JC011854.

Zhang, Y., Y. Du, S. Zheng, Y. Yang, and X. Cheng, 2013: Impact of Indian Ocean dipole on the salinity budget in the equatorial Indian Ocean. J. Geophys. Res. Oceans, 118, 4911-4923, https://doi.org/10.1002/jgrc.20392.

$\longrightarrow, \ldots$, and T. Qu, 2016: A sea surface salinity dipole mode in the tropical Indian Ocean. Climate Dyn., 47, 2573-2585, https://doi.org/10.1007/s00382-016-2984-z.

Zhuang, W., M. Feng, Y. Du, A. Schiller, and D. Wang, 2013: Lowfrequency sea level variability in the southern Indian Ocean and its impacts on the oceanic meridional transports. J. Geophys. Res. Oceans, 118, 1302-1315, https://doi.org/ 10.1002/jgrc.20129. 